\title{
Formação de recursos humanos em saúde da família: paradoxos e perspectivas
}

\author{
Human resources training in family health: \\ paradoxes and perspectives
}

\footnotetext{
1 Centro de Ciências da Saúde, Universidade Estadual de Londrina, Londrina, Brasil.

2 Escola Nacional de Saúde Pública, Fundação Oswaldo Cruz, Rio de Janeiro, Brasil.

Correspondência C. R. R. Gil

Departamento de Saúde Coletiva, Centro de Ciências da Saúde, Universidade Estadual de Londrina. Av. Rio de Janeiro 1643 apto. 702, Londrina, $P R$ 86010-150, Brasil. reginagil@uol.com.br
}

\begin{abstract}
This article presents a profile of former students in both a Fellowship and a Multidisciplinary Residency in Family Health funded by the REFORSUS Project of the Brazilian Ministry of Health and inaugurated in 2001. The survey covered 16 fellowships (38.0\%) and 9 residencies (69.0\%), analyzing 873 questionnaires (709 and 164, respectively). Students in both programs were predominantly females and nurses, having finished their undergraduate training within five years previously. In the Fellowship, the majority of the students were professionals participating in the Family Health teams; one-third of the students had already finished other fellowships, unlike the students in the Multidisciplinary Residency. This type of study helped characterize the student body enrolled in lato sensu graduate training programs and to adjust the supply of such courses to the demand.
\end{abstract}

Health Occupations Manpower; Staff Development; Family Health

\section{Introdução}

O Programa Saúde da Família (PSF), teve início, em 1994, como um dos programas propostos pelo governo federal aos municípios para implementar a atenção básica. Hoje, dez anos depois de sua criação, é tido como uma das principais estratégias de reorganização dos serviços e de reorientação das práticas profissionais neste nível de assistência. Traz, portanto, em seu bojo, muitos e complexos desafios a serem superados para consolidar-se enquanto tal.

No âmbito da reorganização dos serviços de saúde, a estratégia da saúde da família vai ao encontro dos debates e análises referentes ao processo de mudança do paradigma que orienta o modelo de atenção à saúde vigente $\mathrm{e}$ que vem sendo enfrentada, desde a década de 1970 , pelo conjunto de atores e sujeitos sociais comprometidos com um novo modelo que valorize as ações de promoção e proteção da saúde, prevenção das doenças e atenção integral às pessoas.

Estes pressupostos, tidos como capazes de produzir um impacto positivo na orientação do novo modelo e na superação do anterior, calcado na supervalorização das práticas da medicina curativa, especializada e hospitalar, e que induz ao excesso de procedimentos tecnológicos e medicamentosos e, sobretudo, na fragmentação do cuidado, encontra, em relação aos recursos humanos para o Sistema Único de Saú- 
de (SUS), um outro desafio. Tema também recorrente nos debates sobre a reforma sanitária brasileira, verifica-se que, ao longo do tempo, tem sido unânime o reconhecimento acerca da importância de se criar um "novo modo de fazer saúde".

Tem sido constatado que o perfil dos profissionais formados não é adequado o suficiente para prepará-los para uma atuação na perspectiva da atenção integral à saúde e de práticas que contemplem ações de promoção, proteção, prevenção, atenção precoce, cura e reabilitação. Estas preocupações estão refletidas nos relatórios das Conferências Nacionais de Recursos Humanos de 1986 e 1993, assim como no documento Norma Operacional Básica de Recursos Humanos para o SUS (NOB/RH/ SUS), documentos que refletem a posição de um conjunto representativo de segmentos e atores sociais em torno deste tema 1,2,3.

Esses dois processos - modelo de atenção e recursos humanos - são difíceis de discutir separadamente e, ainda que se avalie como de imprescindível importância a discussão em torno da formação de recursos humanos para o SUS, tão importante quanto, é encontrar as melhores alternativas para enfrentar a situação dos profissionais já inseridos no sistema, minimizando os efeitos da formação inadequada dos profissionais e buscando meios de garantir que suas práticas atendam os desafios que estão sendo colocados para a implementação do sistema, em especial no âmbito dos municípios.

Autores do campo da administração, como Vergara 4 e Motta 5 , destacam que pessoas são os recursos mais importantes para se produzir (ou não) mudanças no interior de uma organização. Para eles, os processos de mudanças são construções sociais e, na sociedade contemporânea, as instituições sociais (famílias, escolas, organizações e empresas) têm vivenciado uma democratização crescente em seus interiores. Daí a importância de, nos processos de mudanças, valorizar a gestão das pessoas nos ambientes de trabalho.

Para Sayd et al. 6 (p. 167) "as atividades de assistência à saúde, componentes do setor terciário, possuem particularidades bastante relevantes quanto aos princípios e regras que regem seu exercício e sua legitimidade na sociedade". À parte das questões políticas e culturais que mantiveram a hegemonia do modelo flexneriano predominante na sociedade como um todo, as especificidades do trabalho neste âmbito são mais nítidas. Para os autores, se observa o opos- to em relação às ações no campo da saúde pública que, além de não serem tão claramente definidas, são socialmente pouco reconhecidas e desvalorizadas. Esta reflexão corrobora o que Starfield 7 e Schraiber (1996, apud Mendes 8) apontam em relação à especificidade das características do trabalho na atenção primária que, por sua vez, pode-se estender à própria saúde da família. Para Starfield 7 (p. 52-3) “(...) os médicos de atenção primária, quando comparados com especialistas, lidam com uma variedade mais ampla de problemas, tanto com pacientes individuais como com a população com a qual trabalham. Como estão mais próximos do ambiente do paciente do que os especialistas, estão em uma posição melhor para avaliar o papel dos múltiplos e interativos determinantes da doença e da saúde”.

Em que pese a análise estar dirigida aos profissionais médicos, considera-se que a reflexão acima aplica-se ao conjunto dos profissionais que compõem as equipes de saúde da família. Em tese, todos os que atuam neste âmbito da atenção, deveriam estar aptos para compreender e agir sobre os determinantes do processo saúde/doença, o que implicaria realizar uma síntese de saberes a serem utilizados na definição dos cuidados dos indivíduos e famílias. Entretanto, as práticas profissionais impressas pelo modelo flexneriano não valorizam tal percepção, limitando o cuidado às práticas pontuais e curativas.

Campos \& Aguiar 9, Bevilacqua \& Sampaio 10, Cordeiro 11 e Paim \& Teixeira (comunicação pessoal) trazem importantes elementos para reflexões à área de recursos humanos para o SUS. As análises, embora mais afetas à formação médica, discutem questões relevantes com as quais a saúde da família está se confrontando. São elas: a tendência à superespecialização dos profissionais; a distribuição geográfica, principalmente dos médicos (com destaque para a continuidade dos problemas de interiorização destes profissionais); o distanciamento entre as políticas de formação e a política de saúde (com destaque para as dificuldades de definir o perfil profissional ao término da graduação); a produção de inovações no âmbito das instituições de ensino traduzidas em reformas curriculares mais efetivas (limitações referentes aos docentes onde se observa que, na grande maioria das vezes, eles reproduzem, no ensino, suas condições de trabalho e não as dos serviços existentes e necessários ao mercado, como a saúde da família, por exemplo); e a reor- 
ganização de serviços, em especial, os da atenção básica, fato observado com a expansão da saúde da família, entre outros.

Pierantoni 12 argumenta que as proposições para a área de recursos humanos em saúde apresentam questões mescladas por novos e antigos problemas que abrigam interesses múltiplos e diversificados, indo desde o extremo da reivindicação pela antiga isonomia salarial até o gerado pela sociedade pós-industrial. No entanto, na perspectiva da consolidação do SUS, é importante manter o foco nos avanços já obtidos, e um fato a se considerar é que ele tem possibilitado ampliar o mercado de trabalho dos profissionais de saúde num movimento crescente desde a década de 80 . Neste contexto, cabe reconhecer que a saúde da família tem contribuído, em boa medida, para estes resultados, afinal são médicos, enfermeiros, auxiliares de enfermagem, agentes comunitários, odontólogos, assistentes de consultórios e técnicos em higiene dental que têm sido absorvidos pelos sistemas municipais de saúde.

Nesta mesma perspectiva, Machado 13 (p. 228) afirma que: “(...) esse setor [saúde] gera na ordem de 2 milhões de empregos diretos em saúde (...) e continua sendo, em plena era tecnológica, que se caracteriza pela redução do uso de mão-de-obra, um setor gerador de empregos (...). Tomando os dados recentes disponíveis do IBGE, observamos (...) um crescimento da esfera municipal (...). O setor privado reduz sua importância e passa a representar $41,3 \%$ do total dos estabelecimentos de saúde e, o setor público $58,7 \%$, sendo que a esfera municipal representa $54,2 \%$, configurando assim, o real processo de municipalização do sistema de saúde brasileiro".

No entanto, essa mesma autora, ao analisar o perfil dos médicos no Brasil, encontra que $75,6 \%$ dos médicos têm no mínimo três atividades laborais. Em relação aos médicos e enfermeiros da saúde da família, a situação é mais preocupante uma vez que os dados mostram pouca qualificação dos profissionais, sendo que, cerca de $70,0 \%$ dos médicos e enfermeiros que atuam na saúde da família não possuem nenhuma formação de pós-graduação 13.

Considerando que a saúde da família está efetivamente incorporada à atenção básica, que deixou para trás o rótulo de programa vertical e tem hoje um papel potencial de eixo norteador da organização dos sistemas municipais de saúde (haja vista que a saúde da família não foi descartada no processo de sucessão presidencial de 2002) e que sua expansão tem sido contínua, com medidas, inclusive, de ampliação específica aos municípios com mais de $100 \mathrm{mil}$ habitantes, como é o caso do Projeto de Expan- são da Saúde da Família (PROESF) 14, por exemplo, é de fundamental importância o investimento nas políticas de recursos humanos voltadas às necessidades dos profissionais que atuam nas equipes.

Neste sentido, o Ministério da Saúde, junto com a criação do Piso da Atenção Básica (PAB), que contemplava em uma de suas modalidades o incentivo à expansão do PSF, criou, ainda em 1998, por meio do Departamento de Atenção Básica (DAB), um projeto dinamizador para a implementação da saúde da família - os Pólos de Capacitação, Formação e Educação Permanente em Saúde da Família - cuja concepção orientadora foi a de fortalecer a articulação ensino-serviço em torno, principalmente, das necessidades de capacitação dos profissionais de saúde inseridos nas equipes.

Os Pólos, entendidos como uma estratégia operacional para o desenvolvimento de habilidades dos profissionais de saúde da família na abordagem da atenção integral, destinavam-se a promover ações em três vertentes: capacitação, formação e educação permanente, sempre buscando reforçar a articulação entre as instituições de ensino superior e médio e os serviços estaduais e municipais de saúde. Desta forma, este pool de instituições estaria se comprometendo com o desenvolvimento de recursos humanos para a saúde da família e também para a atenção básica do SUS.

Entre as ações propostas para os Pólos, a realização dos cursos introdutórios visando à capacitação das equipes na lógica do PSF foi a que predominou. $\mathrm{O}$ aumento acelerado do número de equipes somado à alta rotatividade dos profissionais, foi determinante para a priorização desta ação 15. Entretanto, como apenas os cursos introdutórios não eram suficientes para abarcar o espectro de atuação esperada, principalmente dos profissionais de nível superior, foram propostas outras iniciativas com o objetivo de expandir as ações de capacitação e formação dos profissionais. Nesta perspectiva o Ministério da Saúde lançou, em 2000, uma convocatória nacional com o objetivo de implementar a oferta de cursos de pós-graduação lato sensu, nas modalidades de especialização e residência multiprofissional em saúde da família, mediante incentivos financeiros repassados às universidades e escolas de saúde pública das Secretarias Estaduais de Saúde.

No Brasil, a implantação de cursos de especialização na área de saúde como estratégia de fortalecimento de políticas públicas tem sido uma prática habitualmente utilizada pelo Ministério da Saúde. Estudos como o de Labra 16 e Nunes 17 exemplificam iniciativas distintas 
no campo da formação de especialistas com o intuito de criar ou fortalecer determinadas "culturas" no campo da saúde pública quando torna-se necessário difundi-las ou expandi-las para garantir avanços técnicos e políticos.

Segundo demonstra Labra 16, ao resgatar importante fase da história da saúde pública no país, esta prática vem sendo adotada desde o início do século passado, em meados dos anos 20. Naquele período, por exemplo, era preciso formar um quadro de profissionais para atuar na área e uma das principais medidas adotadas pelo governo federal foi a criação de cursos de higiene e saúde pública para formar sanitaristas. Mais adiante, Nunes 17, ao analisar um período mais recente da história, compreendido entre as décadas de 70 e 80 , recupera outras situações nas quais a necessidade de formação de quadros de especialistas em saúde pública fez-se presente.

Em um dos períodos abordados, meados dos anos 80, a autora retrata a necessidade de formação de especialistas para atuar e apoiar o movimento de desconcentração do sistema de saúde, fruto da crise financeira da Previdência Social e da implantação da estratégia das Ações Integradas de Saúde (AIS). Naquele momento, uma das medidas adotadas foi a ampliação da oferta da especialização por meio dos Cursos Descentralizados de Saúde Pública, promovidos pela Escola Nacional de Saúde Pública da Fundação Oswaldo Cruz e ministrados, concomitantemente, em vários estados brasileiros.

Nesta mesma linha, os cursos de Especialização e Residência Multiprofissional em saúde da família foram concebidos para dar suporte teórico-prático aos profissionais já inseridos nas equipes e oferecer, em especial, aos recémegressos dos cursos de medicina e enfermagem, uma formação mais voltada às necessidades do PSF. Outro objetivo esperado era estimular, no interior das universidades e escolas estaduais de saúde pública, a inserção deste tema nos programas de pós-graduação lato sensu 18.

Esses cursos foram viabilizados com recursos do Projeto Reforço à Reorganização do SUS (REFORSUS), por meio de um processo de licitação internacional. O REFORSUS havia destinado $\mathrm{R} \$ 157,2$ milhões para projetos estratégicos do Ministério da Saúde e deste total, R\$7,1 milhões e R \$33,6 milhões foram para a implantação dos cursos de especialização e residência multiprofissional respectivamente, num total de $\mathrm{R} \$ 40,7$ milhões. Este volume representou $25,8 \%$ do total de recursos destinados a investimentos estratégicos no SUS, valendo ressaltar que os mesmos foram destinados exclusivamente para o desenvolvimento de recursos humanos para a saúde da família (Projeto REFORSUS: investimentos em projetos estratégicos. http://www.saude.gov.br, acessado em 17/ Mar/2003).

Para o acompanhamento dos contratos foi constituída uma comissão multiprofissional Comissão de Acompanhamento e Avaliação dos Cursos de Pós-graduação Lato sensu em Saúde da Família - que, por meio de realização de visitas às instituições contratadas, deu início a um processo de avaliação dos mesmos. Entre os objetivos previstos para o trabalho dessa Comissão, estava o de "conhecer o perfil da clientela dos cursos de Especialização e Residência Multiprofissional", considerando-o estratégico para conhecer quem são os agentes que hoje atuam na saúde da família e para que o Ministério da Saúde possa promover a adequação necessária aos programas de desenvolvimento dos profissionais inseridos nas equipes de saúde da família.

Nesta perspectiva, este artigo propõe-se a apresentar a sistematização dos resultados encontrados, caracterizando o perfil dos profissionais que freqüentaram os primeiros cursos de Especialização e de Residência Multiprofissional ofertados pelo Ministério da Saúde. Com os resultados e discussões aqui apresentados, espera-se agregar subsídios à análise das políticas de recursos humanos voltadas ao fortalecimento da Atenção Básica do SUS, em especial, à saúde da família.

\section{Materiais e método}

Este estudo é do tipo transversal e descritivo e sua realização deu-se com base no levantamento realizado pela Comissão de Acompanhamento e Avaliação dos Cursos de Pós-graduação Lato Sensu em Saúde da Família (Especialização e Residência Multiprofissional), citada anteriormente e da qual a autora foi membro integrante.

Para conhecer o perfil dos profissionais/ alunos inseridos nos cursos, foi elaborado e aplicado um questionário semi-estruturado, contendo questões fechadas e abertas e espaços dirigidos a comentários livres dos alunos sobre suas impressões pessoais sobre o desenvolvimento dos cursos.

Os critérios estabelecidos pela Comissão para a realização das visitas foram: terem cumprido a agenda de início dos cursos; estarem com os respectivos contratos do REFORSUS (entrega de documentação) regulares; e estarem em dia com o cumprimento das etapas legais previstas nos contratos (etapas de desenvolvi- 
mento dos cursos). Foram descartados os cursos que estavam em fase de negociação contratual ou com processos jurídicos pendentes no Ministério da Saúde.

Nestes critérios, dos cursos de Especialização em desenvolvimento, nove foram excluídos restando 42 que se enquadraram nos critérios estabelecidos pela Comissão, ou seja, $82,0 \%$ do total de cursos. Destes, 16 foram selecionados aleatoriamente para o início das visitas, representando $38,0 \%$ dos cursos em perfeito andamento. Foram visitados 6 cursos na Região Sul, 2 na Região Sudeste, 4 na Região Centro-Oeste e 4 na Região Nordeste. Alguns deles tinham mais de uma turma o que contabilizou, ao todo, 21 turmas de Especialização visitadas. O universo de análise foi de 709 questionários, com uma perda de 5,0\% dos mesmos, correspondendo aos alunos que estavam ausentes ou não responderam o questionário no dia da visita.

Em relação à Residência Multiprofissional, as dificuldades foram maiores. Dos 26 contratos previstos, apenas 13 , ou seja, 50,0\%, tinham iniciado suas atividades no ano letivo de 2002, sendo que os outros 50,0\% ficaram excluídos das visitas pelos critérios estabelecidos. Foram visitados 9 deles, o que significou 69,0\% dos cursos em andamento e em situação regular, sendo 1 na Região Sul, 2 na Região Sudeste, 2 na Região Centro-Oeste e 4 na Região Nordeste, perfazendo, ao todo, 9 turmas visitadas. $\mathrm{O}$ universo de análise foi de 164 questionários, com uma perda inexpressiva dos mesmos (menos de 2,0\%).

Ao todo foram analisados 873 questionários respondidos pelos alunos de 25 cursos, sendo 7 da Região Sul, 4 da Região Sudeste, 8 da Região Nordeste e 6 da Região Centro-Oeste. As questões fechadas foram processadas com o auxílio do programa pelo Epi Info e as abertas analisadas e tabuladas manualmente.

\section{Resultados e discussão}

\section{Quanto ao sexo}

Do total de alunos pesquisados (873), predominou o sexo feminino com $80,3 \%$ (701) em relação ao masculino com 19,7\% (172). Analisando-se os cursos separadamente, observa-se que os resultados foram semelhantes, ou seja, com predominância para a participação do sexo feminino $(79,1 \%$ na Especialização e $85,4 \%$ na Residência Multiprofissional em contraposição ao masculino com $20,9 \%$ e $14,6 \%$, respectivamente).
Os dados encontrados neste estudo são compatíveis com outros que vêm revelando, entre algumas tendências do mercado de trabalho em saúde, a feminilização das profissões, como os estudos de Girardi \& Carvalho 19; Machado 20 e Escorel 21 sobre os profissionais inseridos nas equipes de saúde da família.

\section{Quanto à idade}

No que se refere à idade, constatou-se que a maioria dos alunos (51,3\%) encontrava-se na faixa etária de 20 a 30 anos, caracterizando a população estudada como de adultos jovens. Em seguida, vêm os que estão na faixa etária de 31 a $40 \operatorname{anos}(28,7 \%)$ e de 41 a 50 anos $(15,7 \%)$. Os cursos de Especialização acompanharam esta distribuição porcentual com 45,3\%, 31,3\% e $8,2 \%$, respectivamente. Porém, nas Residências predominou a faixa etária de 20 a 30 anos $(77,4 \%)$, demonstrando que esses alunos são mais jovens do que os da Especialização. Os dados encontrados estão acima dos valores apontados por Machado 20, nos quais predomina a faixa etária de 30 a 39 anos, com cerca de 40,0\%. No estudo de Escorel 21, em relação aos profissionais de nível superior, encontrou-se uma predominância de profissionais das equipes com idade jovem (abaixo de 30 anos) na maioria dos municípios estudados.

\section{Quanto à formação profissional}

Sobre a formação profissional, observou-se que a categoria de enfermeiros foi a mais encontrada $(58,5 \%)$, seguida pelos médicos $(27,3 \%)$, pelos cirurgiões-dentistas $(8,7 \%)$ e demais categorias que, juntas, representaram 5,5\%. Na Especialização, houve uma maior polarização nos enfermeiros que representaram $61,0 \%$ dos alunos, os médicos $(28,5 \%)$, os cirurgiões-dentistas $(8,3 \%)$ e as demais categorias juntas $2,2 \%$. Nas Residências, os enfermeiros também predominaram, mas em relação à presença dos médicos a diferença foi menor (enfermeiros $48,2 \%$ e médicos $22,0 \%$ ) todavia, observou-se em relação à Especialização uma presença maior dos cirurgiões-dentistas (10,4\%) e das demais categorias profissionais $(19,4 \%)$. Estes dados não puderam ser comparados aos estudos acima referidos uma vez que se trata do perfil dos alunos dos cursos e esta mesma informação, se analisada do ponto de vista da inserção dos mesmos nas equipes, encontra-se na razão de $1: 1$, o que seria o esperado em função das diretrizes de implantação da própria saúde da família.

Entretanto, é importante ressaltar que o esperado seria encontrar uma distribuição mais 
equilibrada entre enfermeiros e médicos, uma vez que estas categorias são as que originalmente compõem as equipes de saúde da família. A menor presença dos médicos demonstra, mais uma vez, a dificuldade para atrair esta categoria ao campo da saúde pública. A baixa presença dos cirurgiões-dentistas pode ser explicada pela inserção mais recente da saúde bucal na saúde da família, porém, mesmo assim, é interessante registrar que a participação desta categoria foi maior do que se esperava, o que pode indicar que o PSF representa a abertura de um novo espaço no mercado de trabalho desta categoria profissional.

\section{Tempo de formado na graduação}

Sobre este item, verificou-se que os alunos tinham, majoritariamente, de 1 a 5 anos de formados $(48,7 \%)$ e, somados aos que concluíram seus cursos há menos de 1 ano $(7,7 \%)$ chegouse a um percentual de $56,4 \%$ de alunos com até 5 anos de formados. Estes dados demonstraram um quadro de profissionais relativamente recente no mercado. Nos cursos de Especialização, observou-se que o percentual de recém formados foi bastante pequeno $(3,4 \%)$ e houve um percentual importante de alunos com mais de 15 anos de formados (21,3\%). Na Residência Multiprofissional observou-se o contrário, com uma participação de alunos com menos de 1 ano de formados bem maior que o encontrado na Especialização.

É interessante destacar que ao analisar cada categoria profissional isoladamente, os médicos foram os que apresentaram o maior tempo de formados (mais de 15 anos) não só quando comparados entre si mas também quando comparados às demais profissões. Em contraposição, os enfermeiros e os cirurgiões-dentistas foram os que apresentaram o menor tempo de formados (menos de 1 e até 5 anos).

\section{Atuação profissional atual}

Em relação à atuação profissional no momento da realização dos cursos, observou-se que os alunos eram, na maioria, integrantes das equipes de saúde da família (69,5\%). Entretanto, ao se observar os cursos separadamente, evidenciou-se diferenças importantes entre eles. $\mathrm{Na}$ Especialização, a participação dos alunos inseridos nas equipes do PSF foi majoritária $(79,5 \%)$, ao contrário do que pode ser observado na Residência Multiprofissional onde predominaram alunos recém-formados, não inseridos nas equipes do PSF, ou seja, alunos bolsistas $(67,8 \%)$ que desenvolviam suas atividades de ensino- aprendizagem no PSF, portanto, sem vínculo profissional. Ainda assim, 26,2\% deles eram integrantes das equipes do PSF.

\section{Vínculo de trabalho}

O tipo de vínculo de trabalho predominante entre os alunos foi o de contrato "informal", entendido aqui como os não celetistas e não estatutários, ou seja, os que não asseguram os direitos trabalhistas previstos na legislação. No cômputo geral, predominou na clientela estudada o vínculo informal $(40,4 \%)$, mas cabe destacar a especificidade de cada curso, pois no caso da Residência esta questão ficou prejudicada uma vez que os alunos eram predominantemente bolsistas. Na Especialização, verificou-se que $47,0 \%$ dos alunos tinham contratos temporários, por prestação de serviços e cargos comissionados, em contraposição a 26,4\% que estavam no regime estatutário e $21,6 \%$ no da CLT (Consolidação das Leis do Trabalho) e, portanto, com direitos e estabilidade no emprego mais assegurados.

Somados os percentuais dos profissionais com vínculos celetista e estatutário $(26,4 \%$ e $21,6 \%)$ constatou-se que a situação vínculos precários versus vínculos formais era da razão de aproximadamente 1:1 (47,0\% versus $48,0 \%)$. Estes dados, por um lado, apontaram um esforço de muitos gestores no processo de implementação do PSF e, por outro, confirmaram que este é um dos principais nós críticos da saúde da família, corroborando queixas e questionamentos de diferentes segmentos preocupados com a precariedade do vínculo de trabalho no PSF. A este fato tem-se atribuído as causas da alta rotatividade das equipes e, conseqüentemente, o comprometimento de todo o arcabouço da estratégia, impedindo a formação de vínculos e o desenvolvimento de novas práticas profissionais que contribuam para a inversão do atual modelo de atenção à saúde. Estes dados são reforçados pelos encontrados por Machado 20 e Escorel 21. As autoras apontam estas mesmas tendências evidenciando, em seus estudos, a fragilidade dos vínculos e a insegurança das equipes.

Nos espaços abertos destinados aos comentários livres dos alunos, esta questão motivou várias manifestações, principalmente dos alunos da Especialização que, como citado anteriormente, são os que estão mais vinculados ao PSF. Foi apontada a urgência de o Ministério da Saúde propor a revisão das formas de contratação dos profissionais. 
Experiência anterior de trabalho e capacitações anteriores

Estas questões procuraram traçar um mapa da trajetória profissional e dos cursos e capacitações já realizados pelos alunos que estavam freqüentando os cursos de Especialização e Residência Multiprofissional. Observou-se que na Especialização 27,6\% dos alunos pesquisados iniciaram suas atividades profissionais em hospitais, migrando posteriormente para o PSF. Para $24,1 \%$, o PSF está sendo o primeiro emprego e $15,2 \%$ estavam em unidades básicas de saúde ou similares antes de irem para as equipes de PSF. Na Residência, observou-se que para a maioria $(87,0 \%)$, o PSF está sendo uma primeira experiência profissional, ainda que ligada ao ensino.

Em relação ao processo de formação, pesquisou-se a participação dos alunos em capacitações realizadas pelos Pólos assim como em outros cursos de Especialização e Residência, à parte destes. No caso específico da Especialização, o que se observou foi que uma grande parcela dos alunos já havia feito o Curso Introdutório (70,0\%); a capacitação no Sistema de Informações da Atenção Básica - SIAB (33,0\%) e a de Atenção Integral às Doenças Próprias da Infância - AIDPI (21,0\%). Em relação à Residência, observou-se que estas capacitações específicas faziam parte dos conteúdos do curso.

Ainda, entre os alunos da Especialização, verificou-se que vários já haviam feito outras especializações: $39,0 \%$ eram especialistas em saúde pública ou saúde coletiva; $23,6 \%$ eram especialistas em outras áreas, tais como: Endodontia, Gestão de Serviços, Materno-Infantil, Gerência de unidades básicas; 11,0\% tinham Residência em outras áreas: Pediatria, Ginecologia e Obstetrícia, Clínica Médica, Anestesiologia, Cardiologia, Moléstias Infecciosas, Medicina Geral e Comunitária, Reumatologia, Psiquiatria, Medicina Tropical e Homeopatia e ainda, 1,8\% dos alunos tinha curso de Mestrado concluído.

Destaca-se que predominou entre os médicos a formação em especialidades clínicas, sendo que uma minoria tinha residência em Medicina Geral e Comunitária, Medicina Preventiva ou especialização em saúde pública ou coletiva o que reafirma a dificuldade de atrair esta categoria para o campo da saúde pública. $\mathrm{O}$ contrário foi observado entre os enfermeiros e cirurgiões-dentistas, para os quais os cursos de especialização em saúde pública ou saúde coletiva foram predominantes.

No que se refere à Residência Multiprofissional, os dados não foram tão expressivos. Para grande parte desta clientela a Residência es- tava sendo a principal formação em pós-graduação lato sensu.

Estas informações permitem inferir que os alunos da Especialização, apesar do pouco tempo de formados, têm uma trajetória permeada por muitas capacitações pontuais em diferentes cursos, tanto os mais voltados para as práticas da saúde da família como em outros de formação em pós-graduação lato sensu. Entretanto, não se observa uma "continuidade ou carreira” em seus processos de formação, uma vez que a especialização stricto sensu não foi referida pela maioria deles.

Estes dados vão ao encontro dos estudos de Machado 20 e Escorel 21, e demonstram os diferentes perfis de formação dos profissionais, sendo o do médico predominantemente clínica e o dos enfermeiros mais voltado à saúde pública, ou seja, reafirmam a formação profissional tradicional de cada categoria e suas trajetórias distintas.

Em que pese a diversidade de cursos e capacitações já realizados, no espaço aberto para comentários dos alunos foram registradas opiniões deles tais como: "o Ministério da Saúde deveria ampliar a chance para os profissionais se especializarem ofertando além da especialização, cursos de mestrado e doutorado". Este depoimento reafirma os dados encontrados neste estudo e confirmados pelos estudos de Machado 20 e Escorel 21 de que o número de profissionais médicos e enfermeiros em saúde da família com formação stricto sensu é ainda muito reduzido.

\section{Considerações finais}

Os dados encontrados neste estudo revelam uma população de alunos/profissionais jovens, com menos de 30 anos, majoritariamente do sexo feminino e enfermeiros, com até 5 anos de formados, inseridos nas equipes de saúde da família e portadores de vínculos empregatícios informais, precários. Os médicos são os que mais tempo têm de formados, ao contrário dos enfermeiros e cirurgiões-dentistas. Estes profissionais têm buscado "especializações" ao longo da trajetória profissional, sendo que os enfermeiros são especialistas em saúde pública ou saúde coletiva e grande parte dos médicos são clínicos, com formação nas especialidades clássicas e poucos têm formação nas áreas da saúde pública. Em relação ao perfil dos alunos, predominou, na Residência Multiprofissional, a inserção de recém-egressos da graduação e na Especialização, profissionais já inseridos nas equipes de saúde da família. 
Outra constatação foi a de que a categoria médica se fez menos presente em ambos os cursos. Este fato reitera a necessidade de se pensar estratégias específicas para atrair o médico para o PSF. Algumas iniciativas de capacitação para essa categoria têm sido buscadas por municípios como Curitiba, Londrina e Cuiabá, entre outros, mais voltadas ao desenvolvimento de habilidades clínicas específicas para o trabalho em atenção primária e saúde da família. Estudá-las, sem preconceito, é um dos desafios a serem enfrentados quando se tem o compromisso de buscar alternativas para melhorar a resolutividade e a qualidades dos serviços.

Os dados encontrados remetem à reflexão sobre a efetividade das capacitações para o desempenho das funções cotidianas dos profissionais da atenção básica. No caso da saúde da família, o objetivo apresentado para a realização destes cursos foi o de "implementar a formação dos profissionais de nível superior, especialmente médicos e enfermeiros, para uma atuação mais voltada às atividades clínico-assistenciais aplicadas no cuidado direto aos indivíduos e famílias, em seu ambiente familiar e social". Entretanto, observa-se, ainda, no contexto brasileiro, muita indefinição quanto às competências e práticas profissionais esperadas para a atuação na atenção básica e, em especial, na saúde da família.

\section{Resumo}

O artigo apresenta o perfil dos alunos ingressos nos cursos de Especialização e na Residência Multiprofissional em saúde da família, ambos financiados pelo Projeto REFORSUS do Ministério da Saúde e iniciados no ano de 2001. Foram pesquisados 16 cursos de especialização (38,0\%) e 9 residências $(69,0 \%)$ mediante análise de 873 questionários (709 e 164, respectivamente). Em ambos predominaram alunos do sexo feminino, enfermeiros e profissionais com até cinco anos de formados. Na Especialização, os profissionais inseridos nas equipes de saúde da família representaram a maioria e verificou-se que cerca de um terço dos alunos já havia feito outros cursos de especialização, observando-se o contrário na Residência Multiprofissional. Concluiu-se que este tipo de estudo contribui para caracterizar a clientela que tem demandado aos cursos de pós-graduação lato sensu, adequando necessidade e oferta.

Recursos Humanos em Saúde; Desenvolvimento de Recursos Humanos; Saúde da Família
Por outro lado, a nosso ver, estas experiências, principalmente nas Residências Multiprofissionais mais do que na própria Especialização, podem representar oportunidade para uma reflexão organizada em torno de alternativas que permitam rever os caminhos para a formação dos profissionais, na perspectiva de um trabalho mais integrado, em equipe, com troca mais efetiva de saberes e práticas. Neste sentido, avalia-se como de fundamental importância, a exemplo do estudo realizado por Hartz \& Camacho 22, investir no aperfeiçoamento e sistematização das avaliações de cursos, para que os avanços alcançados sejam disseminados. Conhecer os "arranjos", as alternativas e os resultados que os cursos (e as Instituições de Ensino Superior) estão realizando para atender às necessidades de formação de recursos humanos em saúde da família, hoje presentes no cenário sanitário brasileiro, é fundamental para os avanços rumo às novas práticas profissionais em saúde.

Por outro lado, é importante ter-se claro que o problema decorrente da fragilidade dos vínculos empregatícios das equipes tem influência direta nesta questão, pois, dar mais estabilidade aos profissionais pode significar aumentar a possibilidade de acúmulo de conhecimentos e habilidades que permitam tornar mais consistentes e duradouras também as propostas de formação destes e dos futuros profissionais de saúde da família.

\section{Agradecimentos}

Ao Departamento de Atenção Básica do Ministério da Saúde que viabilizou a coleta dos dados; às docentes da Escola Nacional de Saúde Pública, Dra. Sarah Escorel (orientadora) e Dra. Maria Eliana Labra pelas sugestões na elaboração do artigo, e aos membros da ex-Comissão de Acompanhamento e Avaliação dos Cursos de Especialização e Residência em Saúde da Família/Pólo Nacional de Formação, Capacitação e Educação Permanente em Saúde da Família: Adauto Martins Soares Filho, Carlos Haroldo Piancastelli, Marco Aurélio Da Ros, Maria Eneida de Almeida, Maria Leopoldina de Castro Villas Boas, Milton Menezes Costa Neto e Nadja de Sá Pinto Dantas Rocha. 


\section{Referências}

1. Ministério da Saúde. I Conferência Nacional de Recursos Humanos em Saúde. Relatório final. Brasília: Secretaria de Recursos Humanos, Ministério da Saúde; 1986.

2. Ministério da Saúde. II Conferência Nacional de Recursos Humanos em Saúde. Relatório final. Brasília: Coordenação Geral de Recursos Humanos para o SUS, Ministério da Saúde; 1993.

3. Ministério da Saúde. Princípios e diretrizes para a NOB/RH - SUS. Brasília: Conselho Nacional de Saúde, Ministério da Saúde; 2002.

4. Vergara SC. Gestão de pessoas. São Paulo: Atlas; 2000.

5. Motta PR. Gestão contemporânea: a ciência e a arte de ser dirigente. Rio de Janeiro: Record; 1995.

6. Sayd JD, Vieira Jr. L, Velandia IC. Recursos humanos nas conferências nacionais de saúde (1941 a 1992). Physis (Rio J) 1998; 8:165-98.

7. Starfield B. Atenção primária: equilíbrio entre necessidades de saúde, serviços e tecnologia. Brasília: Organização das Nações Unidas para a Educação, a Ciência e a Cultura; 2002.

8. Mendes EV. Uma agenda para a saúde. São Paulo: Editora Hucitec; 1996.

9. Campos FE, Aguiar RAT. Atenção básica e reforma curricular. In: Negri B, Faria R, Viana ALD, organizadores. Recursos humanos em saúde: política, desenvolvimento e mercado de trabalho. Campinas: Editora Unicamp; 2002. p. 91-9.

10. Bevilacqua RG, Sampaio SAP. As especializações: histórico e projeções. In: Negri B, Faria R, Viana ALD, organizadores. Recursos humanos em saúde: política, desenvolvimento e mercado de trabalho. Campinas: Editora Unicamp; 2002. p. 33-90.

11. Cordeiro H. Os desafios do ensino das profissões de saúde frente às mudanças do modelo assistencial: contribuições para além dos Pólos de Capacitação. Ensaio: Avaliação de Políticas Públicas na Educação 2002; 10:43-54.

12. Pierantoni CR. Recursos humanos e gerência no SUS. In: Negri B, Faria R, Viana ALD, organizadores. Recursos humanos em saúde: política, desenvolvimento e mercado de trabalho. Campinas: Editora Unicamp; 2002. p. 221-56.

13. Machado MH. Mercado de trabalho em saúde. In: Falcão A, Santos Neto PM, Costa PS, Belisário AS, organizadores. Observatório de recursos humanos em saúde no Brasil: estudos e análises. Rio de Janeiro: Editora Fiocruz; 2003.
14. Ministério da Saúde. Projeto de apoio à implementação e consolidação do Programa Saúde da Família no Brasil. Brasília: Departamento de Atenção Básica, Secretaria de Políticas de Saúde, Ministério da Saúde; 2002.

15. Gil CRR. Cerveira MAC, Torres ZF. Pólos de capacitação em saúde da família: alternativas de desenvolvimento de recursos humanos para atenção básica. In: Negri B, Faria R, Viana ALD, organizadores. Recursos humanos em saúde: política, desenvolvimento e mercado de trabalho. Campinas: Editora Unicamp; 2002. p. 103-26.

16. Labra ME. O movimento sanitarista nos anos 20 : da conexão sanitária internacional à especialização em saúde pública no Brasil [Dissertação de Mestrado]. Rio de Janeiro: Escola Brasileira de Administração Pública, Fundação Getúlio Vargas; 1985.

17. Nunes TC. A especialização em saúde pública e os serviços de saúde de 1970 a 1989 [Tese de Doutorado]. Rio de janeiro: Escola Nacional de Saúde Pública, Fundação Oswaldo Cruz; 1998.

18. Ministério da Saúde. Termos de referência para licitação internacional dos cursos de especialização em saúde da família. Brasília: Departamento de Atenção Básica, Secretaria de Políticas de Saúde, Ministério da Saúde; 1999.

19. Girardi SN, Carvalho CL. Mercado de Trabalho e regulação das Profissões de Saúde. In: Negri B, Faria R, Viana ALD, organizadores. Recursos humanos em saúde: política, desenvolvimento e mercado de trabalho. Campinas: Editora Unicamp; 2002. p. 221-56.

20. Machado MH. Perfil dos médicos e enfermeiros do Programa Saúde da Família no Brasil. Brasília: Ministério da Saúde; 2000. (Relatório final).

21. Escorel S. Avaliação da implementação do Programa Saúde da Família em dez grandes centros urbanos. Brasília: Departamento de Atenção Básica, Secretaria de Políticas de Saúde, Ministério da Saúde; 2002. (Relatório final).

22. Hartz ZMA, Camacho LAB. Formação de recursos humanos em epidemiologia e avaliação dos programas de saúde. Cad Saúde Pública 1996; 12 Suppl 2:13-20.

Recebido em 26/Set/2003

Versão final reapresentada em 22/Abr/2004 Aprovado em 27/Set/2004 